\title{
Study on Correlation between Cognitive Impairment and Geriatric Depression or Geriatric Stress
}

\author{
Dae Jin Kim ${ }^{1, \dagger}$, Soo-Young Cho ${ }^{2, \dagger}$, Jeong Su Choi ${ }^{3}$, Min Woo Lee ${ }^{4}$, Eun-Kyung Cho ${ }^{5}$, Se-hee Kang, ${ }^{2,6}$ \\ Suhng Wook Kim ${ }^{6}$ \\ ${ }^{1}$ Department of Neurology, Pusan National University Yangsan Hospital, Yangsan, Korea \\ Department of Neurology, Seoul National University Hospital, Seoul, Korea \\ ${ }^{3}$ Department of Integrated Biomedical and Life Sciences, Graduate School, Korea University, Seoul, Korea \\ ${ }^{4}$ Institute of Health Science, College of Health Science, Korea University, Seoul, Korea \\ 5 Department of Laboratory Medicine, Graduate School of Medicine, Kangwon National University, Chuncheon, Korea \\ ${ }^{6}$ Department of Health and Safety Convergence Science, Graduate School, Korea University, Seoul, Korea
}

\section{인지기능과 노인성 우울, 노인성 스트레스의 연관성에 대한 연구}

\author{
김대진 ${ }^{1, \dagger}$, 조수영 ${ }^{2, \dagger}$, 최정수 ${ }^{3}$, 이민우 $^{4}$, 조은경 ${ }^{5}$, 강세희 $^{2,6}$, 김성욱 $^{6}$ \\ ${ }^{1}$ 부산대학교 양산병원 신경과, ${ }^{2}$ 서울대학교병원 신경과, ${ }^{3}$ 고려대학교 대학원 의생명융합과학과, ${ }^{4}$ 고려대학교 보건과학대학 보건과학연구소, ${ }^{5}$ 강원대학교 \\ 의학과대학원 진단검사의학전공, ${ }^{6}$ 고려대학교 대학원 보건안전융합과학과
}

\begin{abstract}
This study examined the effects of geriatric depression and geriatric stress on cognitive impairment. In particular, the dementia groups were divided into Alzheimer's disease and vascular dementia. A normal group was used as the control group. For each group, the geriatric depression using the geriatric depression scale (GDS) and geriatric stress using the geriatric stress scale (GSS) was compared with the regression and correlation results of cognitive impairment. Statistical tests, such as descriptive statistics, Kruskall-Wallis, correlation analysis, and multiple regression analysis, were performed. For the Alzheimer's group, the GDS and GSS correlated with the cognitive impairment, but only the GDS showed a cause-and-effect relationship with cognitive impairment. In particular, the male group with Alzheimer's disease showed clear confirmation. In addition, geriatric stress was found to be associated with geriatric depression. In conclusion, geriatric depression affects the cognitive impairment directly and geriatric stress affects the cognitive ability indirectly through geriatric depression. In this study, the Alzheimer's disease, vascular dementia, and control groups had a small sample size. Therefore, the external validity in future studies can be increased using a larger sample size for each group.
\end{abstract}

Key words: Alzheimer's disease, Cognitive impairment, Geriatric depression, Geriatric stress, Vascular dementia

This is an Open Access article distributed under the terms of the Creative Commons Attribution Non-Commercial License (http://creativecommons.org/licenses/by-nc/4.0) which permits unrestricted non-commercial use, distribution, and reproduction in any medium, provided the original work is properly cited.

Copyright () 2019 The Korean Society for Clinical Laboratory Science. All rights reserved.
${ }^{\dagger}$ These authors contributed equally to this work as the first co-authors.

Corresponding author: Suhng Wook Kim Department of Health and Safety Convergence Science, Graduate School, Korea University, 145 Anam-ro, Seongbuk-gu, Seoul 02841, Korea Tel: 82-2-3290-5686 Fax: 82-2-940-2829

E-mail: swkimkorea@korea.ac.kr ORCID: https://orcid.org/0000-0001-5522-0447

Received: January 4, 2019 Revised: February 7, 2019 Accepted: February 8, 2019
서 론

치매는 각종 소인으로 인해 뇌기능이 손상되면서 기억력, 언 어능력, 시공간능력, 집중력, 수행능력 등의 인지기능 장애와 함 께 이상행동과 불안, 초조, 우울 등의 심리적 증상 및 일상생활
능력을 손상 받는 질환이다[1]. 치매의 하위 유형은 정확한 원인 은 밝혀지지 않았지만 타우 단백질, 아밀로이드 베타 등이 대뇌 에 축적되면서 뇌 신경세포가 지속적인 손상을 입는 퇴행성 신 경질환인 알츠하이머성 치매(Alzheimer's disease, $\mathrm{AD}$ )로 전 체 치매의 절반 이상을 차지하고[2,3], 다양한 뇌혈관 질환으로 
인해 인지장애가 생긴 경우인 혈관성 치매(vascular dementia, $\mathrm{VD})$ 는 약 20 30\%의 비중을 차지하며 다발경색 치매, 전략적 뇌경색 치매, 피질하 $\mathrm{VD}$ 등으로 구분된다[4].

치매의 증상은 초, 중, 말기로 구분하며 중기 이후 관찰되는 행 동 및 심리증상 장애(behavioral and psychological symptoms of dementia, BPSD)는 치매를 악화시키고 보호자들의 삶의 질에 큰 영향을 주며 치매환자가 보호시설에 수용되는 가 장 큰 이유로 환자 돌봄의 비용증가를 야기시키므로 관심을 가 져야 한다[5]. BPSD의 증상으로는 우울증, 불안 등의 심리증상 과 공격성, 배회, 부적절한 식사 등의 행동증상이 있다[6]. 이중 우울증은 $\mathrm{AD}$ 의 $40 \sim 50 \%$ 에서 관찰되며[7], 우울증이 $\mathrm{AD}$ 의 전 조 증상이라 추정하기도 한다[8]. 또한 $\mathrm{VD}$ 에서는 $\mathrm{AD}$ 보다 더욱 빈번하고 심한 수준의 우울증이 관찰된다고 보고되었다[9].

우울증은 정상노인 $40 \%$ 에서 나타나는 노년기 대표 질병이 며, 우울증 노인은 인지기능 저하가 관찰된다는 연구 결과가 보 고되었고[10], 치매환자는 정상노인보다 정서적 상태 및 인지 기능 등 전반적으로 더 우울한 것으로 알려져 있다[11]. 하지만 지금까지의 연구에서는 치매환자의 인지장애와 우울, 불안과 같은 정서장애간 연관에 대한 조사만 있었고[12, 13], 초, 중년 층과 다른 노년기의 삶에서 발생된 내 - 외적인 환경요소의 변 화로 인한 생활패턴 및 정서의 변화가 가져온 스트레스에 대한 영향이 반영된 연구 결과는 없었다.

우리의 삶은 다양한 인과관계에 의해 형성되며, 우울이란 감 정도 삶의 방식의 변화, 가족문제, 경제적 상황, 신체적 건강상 태, 소외 문제, 주변 환경 등의 여러 스트레스 요소에 대해 민감 한 영향을 받을 수 있고, 이러한 다양한 스트레스로 인한 감정적 이나 생리학적 변화가 기억력의 저하와 인과관계가 있는 것으 로 보고되었다[14]. 이처럼 우울과 함께 스트레스도 기억력 저 하를 기반으로 다양한 정서장애 및 인지적 수행능력들을 악화 시키는 요인으로 가정할 수 있다.

따라서 본 연구에서는 정상 노인과 치매 환자를 대상으로 노 인성 우울뿐만 아니라 노인성 스트레스가 인지기능에 미치는
영향을 알아보고, 서로 연관성을 확인하고자 하였다.

\section{재료 및 방법}

\section{1. 대상}

이번 연구는 2012년 1월부터 2016년 8월까지 서울대학교 병원 신경과를 방문한 환자 중 인지장애와 관련된 신경과적 질 환을 제외한 다른 내과적, 신경과적 질환을 갖지 않는 60 대부터 90대의 노년층을 대상으로 하였다.

기억장애를 포함한 인지장애와 노인성 우울, 노인성 스트레 스를 호소하는 환자를 대상으로 신경심리 검사를 통해 인지적 요소를 평가하고 임상소견, 뇌 영상 촬영 검사, 혈액학적 검사 등으로 인지장애 유발 원인을 밝혀내고 이를 바탕으로 하여 $\mathrm{AD}$ 는 Diagnostic and statistical manual of mental disorders, $4^{\text {th }}$ edition (DSM-IV)과 National institute of neurological and communicative disorders and stroke and the Alzheimer's disease and related disorders associations (NINCDS-ADRDA)의 기준에 의해 진단하였고, $\mathrm{VD}$ 는 National institute of neurological disorders and stroke and the association internationale pour Ia Recherché et l'Ensignement en Neurosciences (NINDS - AIREN) criteria의 기준에 의해 진단하였으며[15], 각 유형의 임상적인 특징은 Table 1에 설명하였다. 연구대상자는 전체 240명이 모집되었고 한국형 간 이정신상태검사(Korean version of mini-mental state exam, $\mathrm{K}-\mathrm{MMSE}$ ) 평가를 통해 정상군 80 명, 치매군 160 명으로 분류하 였다. 또한 치매군 160 명은 앞선 진단기준에 따라 $\mathrm{AD}$ 군 80 명 $\mathrm{VD}$ 군 80 명으로 재분류 하였다. 인구 통계학적인 기준으로 남 자는 113 명(47.1\%), 여자는 127 명(52.9\%)이었고, 평균 연령은 75.4 7.9세로 70대(102명)가 가장 많고 90대(11명)가 가장 적었다. 또한 평균 학력은 고등학교 수준이었으며 초등학교 졸 업(66명)이 가장 많고 중학교 졸업(32명)이 가장 적었다(Table 2). 본 연구는 서울대학병원 의학윤리심의위원회의 승인 하에

Table 1. The clinical features of Alzheimer's disease and vascular dementia

\begin{tabular}{|c|c|c|}
\hline & Alzheimer's disease & Vascular dementia \\
\hline Incidence rate & $80 \%$ of dementia & $10 \%$ of dementia \\
\hline Cause & $\begin{array}{l}\text { Loss of synapses, synaptic dysfunction, } \\
\text { mitochondrial structural and functional } \\
\text { abnormalities, inflammatory responses }\end{array}$ & $\begin{array}{l}\text { Block or reduce blood flow to the brain, } \\
\text { cerebrovascular inadequacy }\end{array}$ \\
\hline Risk factors & ApeE & Hypertension \\
\hline Neuroimaging & Hippocampal atrophy & Multiple infarction, white matter lesions \\
\hline Progression & Slow progression & Gradual progression or sudden (following stroke) \\
\hline Cardinal symptom & $\begin{array}{l}\text { Memory loss, depression, anxiety, } \\
\text { delusions, executive dysfunction }\end{array}$ & $\begin{array}{l}\text { Brain dysfunction of stroke lesions, } \\
\text { depression, mild impairment }\end{array}$ \\
\hline
\end{tabular}


Table 2. The general characteristics of study participants

\begin{tabular}{|c|c|c|c|c|c|}
\hline \multirow{2}{*}{ Characteristics } & \multirow{2}{*}{ Classifications } & \multicolumn{4}{|c|}{ Participants (\%) } \\
\hline & & Total $(\mathrm{N}=240)$ & AD group $(N=80)$ & VD group $(\mathrm{N}=80)$ & Normal $(\mathrm{N}=80)$ \\
\hline \multirow[t]{2}{*}{ Gender } & Male & $113(47.1)$ & $34(42.5)$ & $40(50.0)$ & $39(48.8)$ \\
\hline & Female & $127(52.9)$ & $46(57.5)$ & $40(50.0)$ & $41(51.3)$ \\
\hline \multirow[t]{5}{*}{ Generation } & Sixty & $50(20.8)$ & $14(17.5)$ & $20(25.0)$ & $16(20.0)$ \\
\hline & Seventy & $102(42.5)$ & $21(26.3)$ & $21(26.3)$ & $60(75.0)$ \\
\hline & Eighty & $77(32.1)$ & $37(46.3)$ & $37(46.3)$ & $3(3.8)$ \\
\hline & Ninety & $11(4.6)$ & $8(10.0)$ & $2(2.5)$ & $1(1.3)$ \\
\hline & Mean $\pm S D^{*}$ & $75.4 \pm 7.9$ & $78.1 \pm 8.6$ & $75.9 \pm 7.7$ & $72.2 \pm 6.2$ \\
\hline \multirow[t]{6}{*}{ Educational background } & Un-education & $38(15.8)$ & $18(22.5)$ & $15(18.8)$ & $5(6.3)$ \\
\hline & Elementary & $66(27.5)$ & $21(26.3)$ & $23(28.8)$ & $22(27.5)$ \\
\hline & Middle & $32(13.3)$ & $11(13.8)$ & $11(13.8)$ & $10(12.5)$ \\
\hline & High & $51(21.3)$ & $13(16.3)$ & $22(27.5)$ & $16(20.0)$ \\
\hline & University & $53(22.1)$ & $17(21.3)$ & $9(11.3)$ & $27(33.8)$ \\
\hline & Mean $\pm \mathrm{SD}^{\dagger}$ & $3.1 \pm 1.4$ & $2.9 \pm 1.5$ & $2.8 \pm 1.3$ & $3.5 \pm 1.4$ \\
\hline
\end{tabular}

${ }^{*}$ Average age for participants.

${ }^{\dagger}$ Coding on educational background: Uneducation=0, Elementary=1, Middle=2, High=3, University=4.

Abbreviations: AD, Alzheimer's disease; VD, Vascular dementia.

진행되었다.

\section{2. 인지적 요소 측정}

신경심리 검사를 통해 기억력, 주의 집중력, 언어기능 시공간 구성능력, 계산능력, 이마엽성 기능 등 대뇌 인지영역의 전반적 인 인지기능이 설문지를 통해 평가되었다[16].

\section{1) 한국형 간이정신상태검사(K-MMSE)}

Folestein이 제작한 간이정신상태검사를[17] 한국 실정에 맞 게 번안한 것으로 인지장애를 진단하는 인지기능 측정 검사도 구로 많이 사용되며[18], 시간 지남력, 장소 지남력, 기억 등록 과 회상, 주의집중 및 계산능력, 언어능력, 시공간 구성능력을 평가하게 된다. 신뢰도 있는 검사를 위해 환자의 학력, 나이, 성 별 등에 따라 점수의 평가 기준을 달리 적용하여 질적인 평가를 하였다[19]. 본 연구에서는 정상노인을 25점이상, 치매노인을 25점 미만으로 구분하였다[20].

2) 치매임상평가척도(clinical dementia rating, CDR)

기억력, 지남력, 판단력과 문제해결, 사회활동, 집안생활과 취미, 위생 및 몸치장의 6가지영역을 범주화하고 평가하여 치매 의 심각한 정도를 평가할 수 있다[21]. 각 영역에 따라 CDR 0, $0.5,1,2,3,4,5$ 점으로 점수화하여 전체 치매임상평가척도 (global CDR)로 나타낸다. CDR 0점은 정상, 0.5점은 경도인지 장애 또는 초기 치매의 상태, 1 점 이상은 치매, 3 점 이상은 중증 의 치매로 분류하였다[22].
3) 이마엽 기능검사(frontal assessment battery, FAB)

$\mathrm{K}-\mathrm{MMSE}$ 에서 평가하기 어려운 이마엽성 기능을 세분화한 것으로 $[23,24]$ 추상적 개념화, 정신적 유연성, 계획, 방해에 대 한 민감도, 억제조절, 환경에 관한 자율성 등 6가지 영역으로 범 주화하여 평가할 수 있다. FAB 17점 이상은 정상, 16점 이하는 이마엽성 기능장애, 12 점 이하는 이마-관자엽 치매로 추정할 수 있다.

4) 한국형 도구적 일상생활능력 평가(Korean instrumental activities of daily life, $\mathrm{K}-\mathrm{IADL}$ )

시장보기, 교통수단이용, 돈 관리, 기구사용 및 집안일 하기, 음식 준비, 전화사용, 취미생활, 약 복용, 집안 수리 등으로 평가 항목을 나누어 인지장애가 일상생활에 미치는 영향을 알아보기 위한 설문형 검사로 보호자를 대상으로 한다. 0.0 3.0점으로 점수화 되며 0.43 점을 기준으로 미만이면 정상, 이상이면 그 정 도에 따라 인지장애가 일상생활에 미치는 것으로 평가한다[25].

5) 노인 우울 척도(geriatric depression scale, GDS)

총 30개의 문항으로 0 17점 이하는 정상, 18 20점은 신뢰 도 $66.67 \%$ 의 우울 경향, 21 점 이상은 신뢰도 $85 \%$ 의 우울증으 로 진단되며 항우울제를 고려한다[26].

6) 노인 스트레스 척도(geriatric stress scale, GSS)

총 24 개의 문항으로 가족문제, 경제적 문제, 소외 문제, 후회 문제, 건강 문제 등 5 가지를 스트레스 요인으로 분류하여 평가 한다. 9 개의 문항은 부정형으로 스트레스 척도를 측정하고 15 
개의 문항은 긍정형으로 스트레스 척도를 측정하도록 되어있 고, 0 72점으로 점수화하여 높을수록 스트레스가 높다는 것을 의미한다.

\section{3. 통계 처리}

SPSS version 20.0 통계프로그램(SPSS Inc., Chicago, IL, USA)을 사용하였다. 연령, 성별, 학력 등의 인구통계학적 기준 을 사용하여 각 그룹별 기술 통계량 분석을 실시하였다. 또한 각 그룹에 대한 인지기능 장애와 노인성 우울, 노인성 스트레스의 차이를 비교하기 위해 Kruskall-Wallis로 확인하였고, GamesHowell 검증방법으로 사후분석을 시행하였다. 또한 노인성 우 울과 노인성 스트레스가 인지장애에 미치는 영향과 노인성 스 트레스가 노인성 우울에 미치는 영향을 알아보기 위해 상관분 석과 다중회귀분석을 시행하였다. 연구의 모든 통계분석에 따 른 유의수준은 $P<0.05$ 로 정하였다.

\section{결 과}

1. 인지기능(K-MMSE, $\mathrm{CDR}, \mathrm{FAB}, \mathrm{K}-\mathrm{IADL})$, 노인 우울증(GDS), 노인 스트레스(GSS)의 평가

본 연구에서 사용한 인지기능 변수들 중 K-MMSE와 FAB는 값이 작을수록, $\mathrm{CDR}$ 과 $\mathrm{K}-\mathrm{IADL}$ 은 값이 높을수록 심한 인지장 애를 의미한다. 또한 우울증 변수인 GDS와 스트레스 변수인 GSS는 값이 높을수록 심한 우울증과 스트레스를 의미한다.
집단 간 인지기능 변수들을 비교한 결과 두 치매군이 정상군 보다 심한 인지장애를 보였고 $(P<0.001)$, 집단 간 $\mathrm{GDS}$ 와 $\mathrm{GSS}$ 를 비교한 결과 $\mathrm{VD}$ 군이 $\mathrm{AD}$ 군과 정상군에 비해 심한 우울과 스 트레스 정도를 보였다 $(P<0.001)$. 그러나 GSS 변수를 세부적인 원인으로 분석한 결과 $\mathrm{VD}$ 군이 $\mathrm{AD}$ 군과 정상군에 비해 가족문 제, 경제적 문제, 소외문제에서만 유의한 차이가 있는 것으로 나 타났다 $(P<0.001)$ (Table 2).

\section{2. 인지기능(K-MMSE, $C D R, F A B, K-I A D L)$ 과 노인 우울증(GDS), 노인 스트레스(GSS)의 상관관계}

전체 대상군에서 인지기능 변수와각 $\mathrm{GDS}, \mathrm{GSS}$ 의 상관관계 를 분석한 결과 $\mathrm{K}-\mathrm{MMSE}$ 와 $\mathrm{FAB}$ 에서는 음의 상관관계 $\mathrm{GDS}=$ $-0.268,-0.287)(\mathrm{GSS}=-0.191,-0.209)$ 를, CDR과 K-IADL에 서는 양의 상관관계 $(\mathrm{GDS}=0.252,0.366)(\mathrm{GSS}=0.182,0.263)$ 를 보였다. 세부적으로 $\mathrm{AD}$ 군에서는 $\mathrm{K}-\mathrm{MMSE}$ 와 $\mathrm{FAB}$ 에서는 음 의 상관관계(GDS=-0.281, -0.345) (GSS=-0.299, -0.308)를, $\mathrm{CDR}$ 과 $\mathrm{K}-\mathrm{IADL}$ 에서는 양의 상관관계 $(\mathrm{GDS}=0.253,0.390)$ (GSS=0.231, 0.300)를 보였다. 특히 성별로 분류한 경우 CDR 과 GSS의 상관관계를 제외하고 나머지 인지기능 변수들에서 $\mathrm{GDS}$ 와 GSS가 남성에서만 통계적으로 유의한 상관관계를 확인 하였다. 그러나 또 다른 치매 분류인 $\mathrm{VD}$ 군에서 인지기능 변수 와각 GDS, GSS의 유의한 상관관계 확인할 수 없었고, 정상군에 서도 GDS는 $\mathrm{FAB}, \mathrm{K}-\mathrm{IADL}, \mathrm{GSS}$ 는 K-IADL에서만 유의한 상관 관계를 보였고, 나머지 인지기능 변수들에서는 유의한 상관관

Table 3. Evaluation of cognitive impairment, GDS and GSS for study participants

\begin{tabular}{lcccccc}
\hline \multirow{2}{*}{ Characteristics } & \multicolumn{9}{c}{ Division } & \multirow{2}{*}{ F or $\chi^{2}(P)$} & Post-hoc \\
\cline { 2 - 4 } & Total & AD group (a) & VD group (b) & Normal $(\mathrm{c})$ & & \\
\hline K-MMSE & $19.3 \pm 6.6$ & $15.4 \pm 4.3$ & $15.4 \pm 4.1$ & $27.1 \pm 1.5$ & $<0.001$ & $\mathrm{a}=\mathrm{b}<\mathrm{c}$ \\
CDR & $1.2 \pm 0.8$ & $1.6 \pm 0.8$ & $1.5 \pm 0.8$ & $0.5 \pm 0.1$ & $<0.001$ & $\mathrm{a}=\mathrm{b}>\mathrm{c}$ \\
FAB & $10.1 \pm 4.8$ & $7.2 \pm 3.2$ & $7.9 \pm 3.9$ & $15.3 \pm 2.1$ & $<0.001$ & $\mathrm{a}=\mathrm{b}<\mathrm{c}$ \\
K-IADL & $1.4 \pm 1.1$ & $1.9 \pm 0.9$ & $2.0 \pm 0.9$ & $0.2 \pm 0.3$ & $<0.001$ & $\mathrm{a}=\mathrm{b}>\mathrm{c}$ \\
GDS & $15.8 \pm 7.8$ & $14.9 \pm 7.6$ & $18.9 \pm 7.8$ & $13.6 \pm 7.0$ & $<0.001$ & $\mathrm{a}=\mathrm{c}<\mathrm{b}$ \\
GSS & $9.8 \pm 6.1$ & $8.3 \pm 5.6$ & $12.6 \pm 5.8$ & $8.5 \pm 5.0$ & $<0.001$ & $\mathrm{a}=\mathrm{c}<\mathrm{b}$ \\
Factor1 & $2.6 \pm 2.3$ & $2.0 \pm 2.0$ & $3.4 \pm 2.4$ & $2.3 \pm 2.1$ & $<0.001$ & $\mathrm{a}=\mathrm{c}<\mathrm{b}$ \\
Factor2 & $1.8 \pm 1.7$ & $1.5 \pm 1.6$ & $2.6 \pm 1.6$ & $1.2 \pm 1.5$ & $<0.001$ & $\mathrm{a}=\mathrm{c}<\mathrm{b}$ \\
Factor3 & $2.2 \pm 2.0$ & $2.1 \pm 2.0$ & $3.0 \pm 2.1$ & $1.6 \pm 1.7$ & $<0.001$ & $\mathrm{a}, \mathrm{c}<\mathrm{b}$ \\
Factor4 & $1.0 \pm 1.1$ & $0.7 \pm 1.0$ & $1.1 \pm 1.2$ & $1.0 \pm 1.0$ & 0.058 & \\
Factor5 & $2.1 \pm 1.4$ & $1.9 \pm 1.5$ & $2.3 \pm 1.3$ & $2.0 \pm 1.4$ & 0.163 &
\end{tabular}

Data are presented as mean \pm SD and number.

Continuous value was performed with Kruskall-Wallis.

Post-hoc test was performed with Games-Howell.

${ }^{*}$ Geriatric stress scale category: Factor 1=family problem; Factor 2=finance problem; Factor 3=communication power problem; Factor 4=regret problem; Factor 5=health problem.

Abbreviations: AD, Alzheimer's disease; VD, vascular dementia; K-MMSE, Korean version of mini-mental state exam; CDR, clinical dementia rating; FAB, frontal assessment battery; K-IADL, Korean instrumental activities of daily life; GDS, geriatric depression scale; GSS, geriatric stress scale. 
계를 확인할 수 없었다(Table 3).

\section{3. 노인 우울증(GDS)과 노인 스트레스(GSS)의} 인지기능(K-MMSE, $\mathrm{CDR}, \mathrm{FAB}, \mathrm{K}-\mathrm{IADL})$ 과 인과관계

전체 대상군에서 인지기능 변수와 각 $\mathrm{GDS}, \mathrm{GSS}$ 의 인과관계
를 분석한 결과 GDS만 인지기능 변수들과의 인과관계를 보였 다 $(P=0.006,0.013,0.003,<0.001)$. 또한 세부적으로도 $\mathrm{AD}$ 군에서 $\mathrm{GDS}$ 만 $\mathrm{K}-\mathrm{MMSE}, \mathrm{CDR}, \mathrm{K}-\mathrm{IADL}$ 과의 인과관계를 보였 고 $(P=0.045,0.045,0.006)$, 정상군에서는 $\mathrm{GDS}$ 만 $\mathrm{K}-\mathrm{IADL}$ 과 의 인과관계가 확인되었다 $(P<0.001)$ (Table 4).

Table 4. Correlation between cognitive impairment, GDS and GSS

\begin{tabular}{|c|c|c|c|c|c|c|c|c|c|}
\hline \multirow{2}{*}{\multicolumn{2}{|c|}{ Characteristics }} & \multicolumn{2}{|c|}{ Total } & \multicolumn{2}{|c|}{ AD group } & \multicolumn{2}{|c|}{ VD group } & \multicolumn{2}{|c|}{ Normal } \\
\hline & & GDS & GSS & GDS & GSS & GDS & GSS & GDS & GSS \\
\hline \multirow[t]{3}{*}{ K-MMSE } & Total & $-0.268^{\star \star}$ & $-0.191^{\star \star}$ & $-0.281^{\star}$ & -0.299 & -0.127 & -0.069 & 0.030 & 0.045 \\
\hline & Male & $-0.344^{\star \star}$ & $-0.201^{\star}$ & $-0.549^{\star \star}$ & $-0.403^{\star}$ & -0.238 & -0.166 & -0.119 & -0.093 \\
\hline & Female & $-0.184^{*}$ & -0.151 & 0.015 & -0.033 & -0.111 & 0.000 & 0.077 & 0.134 \\
\hline \multirow[t]{3}{*}{ CDR } & Total & $0.252^{\star \star}$ & $0.182^{\star \star}$ & $0.253^{\star}$ & $0.231^{\star}$ & 0.101 & 0.079 & -0.003 & 0.086 \\
\hline & Male & $0.288^{\star \star}$ & 0.130 & $0.372^{\star}$ & 0.287 & 0.165 & 0.007 & 0.175 & 0.246 \\
\hline & Female & $0.195^{\star}$ & $0.195^{\star}$ & 0.024 & -0.024 & 0.127 & 0.194 & -0.254 & -0.174 \\
\hline \multirow[t]{3}{*}{ FAB } & Total & $-0.287^{\star \star}$ & $-0.209^{\star \star}$ & $-0.345^{\star \star}$ & $-0.308^{\star \star}$ & -0.053 & -0.062 & $-0.268^{\star}$ & -0.119 \\
\hline & Male & $-0.383^{\star \star}$ & -0.171 & $-0.510^{\star \star}$ & $-0.478^{\star \star}$ & -0.176 & 0.014 & $-0.519^{\star \star}$ & -0.045 \\
\hline & Female & $-0.191^{\star}$ & $-0.219^{\star}$ & -0.097 & 0.001 & 0.017 & -0.155 & -0.095 & -0.195 \\
\hline \multirow[t]{3}{*}{$K-I A D L$} & Total & $0.366^{\star \star}$ & $0.263^{\star \star}$ & $0.390^{\star \star}$ & $0.300^{\star \star}$ & 0.192 & 0.121 & $0.330^{\star \star}$ & $0.245^{\star}$ \\
\hline & Male & $0.410^{\star \star}$ & $0.303^{\star \star}$ & $0.543^{\star \star}$ & $0.425^{\star}$ & 0.265 & 0.292 & 0.240 & $0.379^{*}$ \\
\hline & Female & $0.285^{\star \star}$ & $0.193^{\star}$ & 0.144 & 0.095 & 0.108 & -0.102 & $0.407^{\star \star}$ & 0.124 \\
\hline
\end{tabular}

Calculated by Spearman correlation coefficient.

${ }^{\star} P<0.05,{ }^{*} p<0.01$.

Abbreviations: See Table 3.

Table 5. Multiple regression analysis the impact of cognitive impairment on GDS and GSS

\begin{tabular}{|c|c|c|c|c|c|c|c|c|c|c|}
\hline Characteristics & $\begin{array}{l}\text { Independent } \\
\text { variable }\end{array}$ & $\begin{array}{l}\text { Dependent } \\
\text { variable }\end{array}$ & B & SE & $\beta$ & $\mathrm{t}$ & $P$ & $\mathrm{~F}$ & $R^{2}$ & Adj $R^{2}$ \\
\hline \multirow[t]{8}{*}{ Total } & GDS & K-MMSE & -0.184 & 0.067 & -0.217 & -2.75 & $0.006^{\star \star}$ & $8.086^{\star}$ & 0.064 & 0.056 \\
\hline & GSS & & -0.057 & 0.086 & -0.053 & -0.665 & 0.507 & & & \\
\hline & GDS & CDR & 0.021 & 0.008 & 0.2 & 2.513 & $0.013^{*}$ & $6.462^{\star}$ & 0.052 & 0.044 \\
\hline & GSS & & 0.005 & 0.011 & 0.041 & 0.52 & 0.604 & & & \\
\hline & GDS & FAB & -0.147 & 0.048 & -0.239 & -3.04 & $0.003^{\star \star}$ & $9.381^{\star}$ & 0.073 & 0.066 \\
\hline & GSS & & -0.038 & 0.062 & -0.048 & -0.609 & 0.543 & & & \\
\hline & GDS & $\mathrm{K}-\mathrm{IADL}$ & 0.041 & 0.011 & 0.292 & 3.801 & $<0.001^{\star * \star}$ & $15.572^{*}$ & 0.116 & 0.109 \\
\hline & GSS & & 0.013 & 0.014 & 0.072 & 0.943 & 0.347 & & & \\
\hline \multirow{8}{*}{$A D$ group } & GDS & K-MMSE & -0.216 & 0.121 & -0.423 & -1.788 & $0.045^{\star}$ & 2.08 & 0.134 & 0.069 \\
\hline & GSS & & 0.107 & 0.251 & 0.1 & 0.424 & 0.675 & & & \\
\hline & GDS & CDR & 0.046 & 0.022 & 0.492 & 2.102 & $0.045^{*}$ & 2.413 & 0.152 & 0.089 \\
\hline & GSS & & -0.04 & 0.045 & -0.208 & -0.89 & 0.382 & & & \\
\hline & GDS & $F A B$ & -0.161 & 0.098 & -0.378 & -1.634 & 0.114 & 2.766 & 0.17 & 0.109 \\
\hline & GSS & & -0.044 & 0.205 & -0.05 & -0.215 & 0.831 & & & \\
\hline & GDS & K-IADL & 0.078 & 0.026 & 0.637 & 3.001 & $0.006^{* *}$ & $5.842^{\star}$ & 0.302 & 0.25 \\
\hline & GSS & & -0.039 & 0.054 & -0.153 & -0.719 & 0.478 & & & \\
\hline \multirow[t]{8}{*}{ Normal } & GDS & K-MMSE & 0.053 & 0.039 & 0.246 & 1.361 & 0.181 & 0.963 & 0.046 & -0.002 \\
\hline & GSS & & -0.047 & 0.05 & -0.17 & -0.942 & 0.352 & & & \\
\hline & GDS & CDR & -0.003 & 0.004 & -0.147 & -0.805 & 0.425 & 0.569 & 0.028 & -0.021 \\
\hline & GSS & & 0.005 & 0.005 & 0.186 & 1.017 & 0.315 & & & \\
\hline & GDS & FAB & -0.093 & 0.053 & -0.314 & -1.761 & 0.086 & 1.55 & 0.072 & 0.026 \\
\hline & GSS & & 0.065 & 0.069 & 0.168 & 0.941 & 0.352 & & & \\
\hline & GDS & $\mathrm{K}-\mathrm{IADL}$ & 0.027 & 0.007 & 0.601 & 4.106 & $<0.001^{\star \star *}$ & $12.005^{*}$ & 0.375 & 0.344 \\
\hline & GSS & & 0.001 & 0.008 & 0.021 & 0.146 & 0.885 & & & \\
\hline
\end{tabular}

Calculated by multivariable linear regression analysis.

${ }^{*} P<0.05,{ }^{*} * P<0.01,{ }^{*} * * P<0.001$.

Abbreviations: See Table 3. 


\section{4. 노인 스트레스(GSS)의 우울증(GDS)과 인과관계}

Table 3에서 $\mathrm{AD}$ 군은 GDS, GSS가 인지기능 변수와 유의한 상관성을 확인하였지만, Table 4에서 $\mathrm{AD}$ 군은 $\mathrm{GDS}$ 만 $\mathrm{K}-\mathrm{MMSE}, \mathrm{CDR}, \mathrm{K}-\mathrm{IADL}$ 에 유의하게 영향을 미칠 수 있는 원인 이라는 결과가 나왔다. 즉 $\mathrm{GSS}$ 의 경우 인지기능 변수와 상관성 은 확인되나, 영향을 미칠 수 있는 원인이라고는 단정할 수 없 다. 그러나 이전 연구에 따르면 스트레스가 치매의 위험요소로 확인되었고[27-29], 스트레스와 우울의 연관성[30]도 확인되 었다. 이에 본 연구자들은 GSS가 GDS에 미치는 영향을 확인하 면. 간접적으로 GSS와 인지기능 변수들과의 연관성을 예측할 수 있을 것으로 사료되어 GSS와 GDS를 다중회귀분석을 실시 하였다. 그 결과 전체 대상군과 $\mathrm{AD}$ 군, 정상군에서 $\mathrm{GSS}$ 와 $\mathrm{GDS}$ 의 인과관계를 확인되었다 $(P<0.001)$. 특히 GSS를 세부적인 원 인 별로 분석한 결과 전체 대상군에서는 가족, 소외, 건강 $(P=$ $<0.001,<0.001,0.005)$ 에서, $\mathrm{AD}$ 군에서는 가족, 소외 $(P=0.005,0.003)$ 에서, 정상군에서는 소외 $(P=0.021)$ 에서 각각 인과관계를 확인하였다(Table 5).

\section{고 찰}

본 연구에서 나타난 혈관성 치매는 우울증과 스트레스가 높 지만, 인지기능과의 연관성은 관찰할 수 없고, 알츠하이머성 치
매는 우울증이 인지기능에 영향을 미치는 것으로 보인다. 또한 스트레스는 우울증에 영향을 미치는 것으로 확인되며, 간접적 으로 알츠하이머성 치매의 원인이 될 수 있을 것으로 예측된다 (Figure 1). 특히 가족문제와 소외문제가 중요한 원인이 될 수 있 다(Table 6).

의학의 발달과 삶의 질이 높아짐에 따라 고령화 속도가 빨라

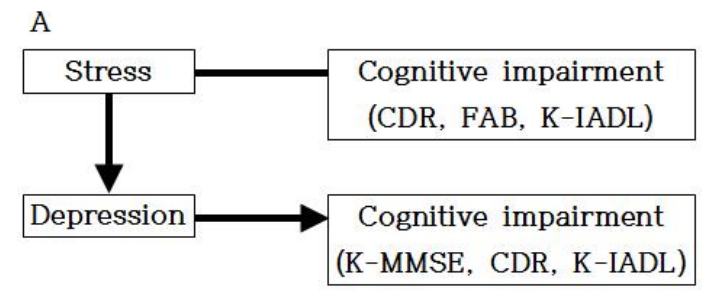

B
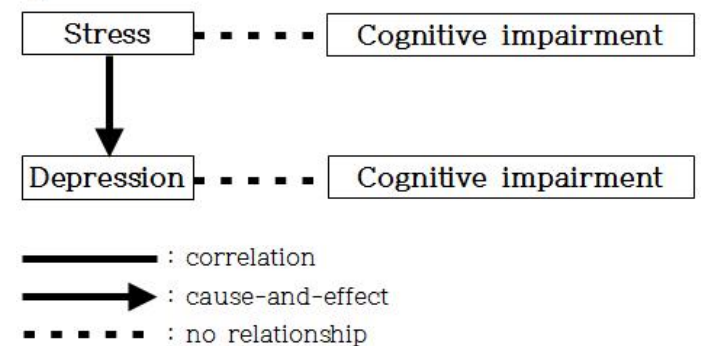

Figure 1. Flow diagram of association between cognitive impairment and GDS or GSS. (A) Alzheimer's disease. (B) Vascular dementia.

Table 6. Multiple regression analysis the impact of GDS on GSS

\begin{tabular}{|c|c|c|c|c|c|c|c|c|c|c|}
\hline Characteristics & $\begin{array}{l}\text { Independent } \\
\text { variable }\end{array}$ & $\begin{array}{l}\text { Dependent } \\
\text { variable }\end{array}$ & B & SE & $\beta$ & $\mathrm{t}$ & $P$ & $\mathrm{~F}$ & $R^{2}$ & Adj $R^{2}$ \\
\hline \multirow[t]{6}{*}{ Total } & GSS & GDS & 0.775 & 0.066 & 0.607 & 11.769 & $<0.001^{\star * *}$ & $138.519^{*}$ & 0.368 & 0.365 \\
\hline & Factor 1 & & 0.8 & 0.206 & 0.234 & 3.886 & $<0.001^{\star \star *}$ & $33.03^{*}$ & 0.414 & 0.401 \\
\hline & Factor 2 & & 0.111 & 0.294 & 0.024 & 0.376 & 0.707 & & & \\
\hline & Factor 3 & & 1.521 & 0.247 & 0.393 & 6.146 & $<0.001^{\star \star \star}$ & & & \\
\hline & Factor 4 & & 0.265 & 0.424 & 0.037 & 0.624 & 0.533 & & & \\
\hline & Factor 5 & & 0.952 & 0.335 & 0.17 & 2.842 & $0.005^{\star \star}$ & & & \\
\hline \multirow[t]{6}{*}{$A D$ group } & GSS & GDS & 0.798 & 0.122 & 0.595 & 6.545 & $<0.001^{\star \star *}$ & $42.837^{\star}$ & 0.355 & 0.346 \\
\hline & Factor 1 & & 1.185 & 0.408 & 0.319 & 2.904 & $0.005^{\star \star}$ & $9.784^{*}$ & 0.398 & 0.357 \\
\hline & Factor 2 & & -0.26 & 0.525 & -0.056 & -0.495 & 0.622 & & & \\
\hline & Factor 3 & & 1.287 & 0.422 & 0.335 & 3.048 & $0.003^{\star \star}$ & & & \\
\hline & Factor 4 & & 0.319 & 0.795 & 0.041 & 0.401 & 0.689 & & & \\
\hline & Factor 5 & & 1.086 & 0.601 & 0.208 & 1.805 & 0.075 & & & \\
\hline \multirow[t]{6}{*}{ Normal } & GSS & GDS & 0.559 & 0.12 & 0.467 & 4.661 & $<0.001^{\star \star *}$ & $21.727^{*}$ & 0.218 & 0.208 \\
\hline & Factor 1 & & 0.688 & 0.425 & 0.207 & 1.62 & 0.11 & & & \\
\hline & Factor 2 & & 0.241 & 0.648 & 0.052 & 0.373 & 0.71 & & & \\
\hline & Factor 3 & & 1.165 & 0.495 & 0.277 & 2.353 & $0.021^{*}$ & $5.075^{\star}$ & 0.255 & 0.205 \\
\hline & Factor 4 & & -0.005 & 0.917 & -0.001 & -0.006 & 0.995 & & & \\
\hline & Factor 5 & & 0.708 & 0.636 & 0.136 & 1.114 & 0.269 & & & \\
\hline
\end{tabular}

Calculated by multivariable linear regression analysis.

${ }^{\star} P<0.05,{ }^{* *} P<0.01,{ }^{* * \star} P<0.001$.

Abbreviations: See Table 3. 
지고 있고, 그에 따른 노인성 질환도 증가하고 있다. 노인성 질 환의 대표적인 치매는 환자뿐만 아니라 부양가족에게도 경제 적, 정신적으로 고통의 부담이 있기에 조기발견이 중요하며, 더 나아가 발병원인을 찾아 예방하는 것이 더욱 중요하다.

본 연구에서는 치매를 유발원인에 따라 $\mathrm{AD}$ 군과 $\mathrm{VD}$ 군으로 구 분하고 정상군을 포함하여 세 군간의 인지기능 저하를 측정하는 변수들과우울증, 스트레스의차이점과, 인지기능 변수와우울증, 스트레스의 연관성도 확인하였다. 집단 간 해당 변수의 차이점을 보면, 인지기능 변수들에서는 두 치매군이 정상군에 비해서 높은 인지기능 장애를 보였지만 $\mathrm{GDS}, \mathrm{GSS}$ 에서는 $\mathrm{VD}$ 군이 $\mathrm{AD}$ 군과 정 상군에 비해서 높은 우울증과 스트레스를 보였다. 이는 이전의 연 구결과와 같이 우울증은 $\mathrm{AD}$ 와 비특이성 치매보다 $\mathrm{VD}$ 에서 좀 더 일반적인 견해라는 점과 같은 결과로 확인되었다[13]. 또한 이전 의 연구들에서는 확인할수 없었던 GSS를 요인 분석한 결과는 VD 환자들이 다른 집단보다 가족문제, 경제문제, 소외문제의 스트레 스 요인이 높다는 점을 확인하여 객관적으로 노인성 스트레스 해 소를 위해 관심을 가져야 할 부분이라 사료된다(Table 2).

$\mathrm{GDS}, \mathrm{GSS}$ 와 인지기능 변수들과의 상관성은 대체적으로 $\mathrm{AD}$ 군에서만 나타났다. 특히 GDS는 남성에서만 인지기능 변수들 과 상관성이 있고(Table 3), GDS가 인지기능 변수들에 영향을 미치는 원인으로 확인되었다(Table 4). 위의 결과는 명확하지 않은 우울증으로 인한 치매의 발현[10]을 뒷받침할 수 있는 결 과로 사료되며, 남성에서 국한된다는 것을 증명하였다. 이전의 연구에서는 성별에 따른 우울증과 인지기능의 연관성에 대해 많이 언급되지 않았지만, Fuhrer에 따르면[31] 남성에서 고혈 압과 같은 혈관의 병리학적인 문제로 인한 우울증은 $\mathrm{AD}$ 의 증상 이 악화되는 것을 가속시킬 수 있고, 최근 발생한 우울증에서만 국한된다고 한다. 이는 남성에서만 우울증과 인지기능 변수들 과 연관성이 있다는 본 연구를 뒷받침할 수 있을 것이고, 우울증 을 기간별로 세분화할 필요성을 제시하였다. GSS의 경우 다른 연구결과[28, 30]와 같이 인지기능과의 연관성은 있었지만 (Table 3), 영향을 미치는 원인이라고는 할 수 없다(Table 4). 그 러나 Table 5에서 보면 GSS의 경우 GDS에 영향을 미치는 원인 이라는 결과를 보면, 스트레스는 직접적으로 인지기능 장애의 원인은 될 수 없으나, 노인성 우울을 유발할 수 있고 그로 인하여 인지기능 장애에 간접적으로 영향을 미치는 것으로 예측할 수 있는 부분이다. 이는 우울증을 감소시키는 것도 치매 예방에 도 움은 되지만, 스트레스가 우울증의 원인이기에 우선적으로 관 리해야 된다고 사료된다. 결론적으로 치매를 조기 진단하는 것 은 매우 중요하며 노인성 우울의 평가를 통해서 $\mathrm{AD}$ 는 어느 정도 예측가능 할 수 있고, 예방적인 차원에서 노인성 스트레스의 관
리가 필요하다.

그러나 본 연구의 제한점은 다음과 같다. 첫째로 다른 질환을 갖지 않은 대상자들의 인구통계학적인 기준으로만 분류하여 조 사되어, 가족력과 치매와 연관된 생활 정도, 직업 등 사회력과 결부되어 좀 더 세분화하지 못해 추가적인 연구가 필요할 것이 다. 둘째로 치매는 환자뿐만 아니라 가족의 역할이 매우 중요하 다. 이번 연구에서는 단편적인 환자의 인지기능과 우울증, 스트 레스와의 연관성을 확인하였지만 가족과의 관계, 가족들의 스 트레스와 우울 정도 등을 복합적으로 분석하는 것이 좀 더 완성 도 높은 연구가 될 것이라 사료된다.

\section{요 약}

본 연구의 목적은 노인성 우울, 노인성 스트레스와 인지기능 과의 연관성을 확인하는 것이다. 구체적으로 치매를 유발 원인 에 따라 알츠하이머성 치매와 혈관성 치매의 두 그룹으로 분류 하고 각 그룹의 인지장애 및 노인성 우울, 노인성 스트레스의 정 도와 특성의 차이를 확인하고 상호간의 연관성을 비교하고자 한다. 인지기능의 변수는 한국형 간이정신상태검사, 치매임상 평가척도, 이마엽 기능검사, 한국형 도구적 일상생활능력 평가 를 사용하였고, 노인성 우울변수는 노인우울척도(GDS), 노인 성 스트레스변수는 노인스트레스척도(GSS)를 사용하였다. 통 계적 방법은 알츠하이머성 치매환자 80명, 혈관성 치매환자 80 명, 통제를 위한 정상군 80명을 설정하여 기술 통계량, Kruskall-Wallis, 상관분석, 다중회귀분석으로 통계적으로 유의한 차이 및 연관성을 확인하였다. 알츠하이머성 치매군에서는 $\mathrm{GDS}, \mathrm{GSS}$ 와 대체적으로 인지기능 변수들과의 상관관계는 확 인하였다. 특히 GDS는 남성에서만 인지기능 변수들과 상관관 계가 있고, 인지기능 변수들과의 인과관계도 확인되었다. 또한 $\mathrm{GSS}$ 와 GDS와의 인과관계를 확인하여 GSS가 GDS의 원인이 된다는 유의성을 확인하였다. 결론적으로 GDS는 알츠하이머 성 치매군에서 인지기능 변수와의 상관관계와 직접적인 인과관 계를 확인하였고, GSS는 직접적인 상관관계보다 GDS를 유발하 여 인지기능 장애와의 간접적인 인과관계를 확인할 수 있었다.

\section{Acknowledgements: None \\ Conflict of interest: None}

Author's information (Position): Kim DJ ${ }^{1, \dagger}$, M.T.; Cho $\mathrm{SY}^{2,}{ }^{\dagger}$, M.T.; Choi JS ${ }^{3}$, Graduate student; Lee MW' ${ }^{4}$, Adjunct professor; Cho EK ${ }^{5}$, M.T.; Kang $\mathrm{SH}^{2,6}$, M.T.; Kim SW', Professor. 


\section{REFERENCES}

1. Dening T, Babu Sandilyan M. Dementia: definitions and types. Nurs Stand. 2015;29:37-42. http://doi.org/10.7748/ns.29.37.37. e9405.

2. Evans DA, Funkenstein HH, Albert MS, Scherr PA, Cook NR, Chown MJ, et al. Prevalence of Alzheimer's disease in a community population of older persons. Higher than previously reported. JAMA. 1989;262: 2551-2556. http://doi.org/10.1001/ jama.1989.03430180093036.

3. Chui HC, Victoroff JI, Margolin D, Jaqust W, Shankle R, Katzman $\mathrm{R}$, et al. Criteria for the diagnosis of ischemic vascular dementia proposed by the state of California Alzheimer's disease diagnostic and treatment centers. Neurology. 1992;42:473-480. http://doi.org/10.1212/WNL.42.3.473.

4. McPherson SE, Cummings JL. Neuropsychological aspects of vascular dementia. Brain Cogn. 1996;31:269-282. http://doi.org/10.1006/brcg.1996.0045.

5. Oh BH. Diagnosis and treatment for behavioral and psychological symptoms of dementia. J Korean Med Assoc. 2009;52:1048-1054. http://doi.org/10.5124/jkma.2009.52.11.1048.

6. Finkel SI, Silva JC, Cohen GD, Miller S, Sartorius N. Behavioral and psychological symptoms of dementia: a consensus statement on current knowledge and implications for research and treatment. Am J Geriatr Psychiatry. 1998;6:97-100. http://doi.org/10.1097/00019442-199805000-00002.

7. Burns A, Jacoby R, Levy R. Psychiatric phenomena in Alzheimer's disease: disorders of behavior. Br J Psychiatry. 1990;157:86-91. http://doi.org/10.1192/bjp.157.1.86.

8. Cummings JL, Mega M, Gray K, Rosenberg-Thompson S, Carusi DA, Gornbein J. The Neuropsychiatric inventory: comprehensive assessment of psychopathology in dementia. Neurology. 1994;44:2308-2314. http://doi.org/10.1212/WNL.44.12.2308.

9. Cummings JL, Miller B, Hill MA, Neshkes R. Neuropsychiatric aspects of multi-infarct dementia and dementia of the Alzheimer type. Arch Neurol. 1987;44:389-393. http://doi.org/ 10.1001/archneur.1987.00520160031010.

10. Korczyn AD, Halperin I. Depression and dementia. J Neurol Sci. 2009;283:139-142. http://doi.org/10.1016/i.ins.2009.02.346.

11. Ryu KH, Kang YW, Na DL, Lee KH, Chung CS. The characteristics of depression in dementia patients. Kor J Clin Psychol. 2000;19:117-129.

12. Nilsson FM, Kessing LV, Sorensen TM, Andersen PK, Bolwig TG. Enduring increased risk of developing depression and mania in patients with dementia. J Neurol Neurosurg Psychiatry. 2002; 73:40-44. http://doi.org/10.1136/jnnp.73.1.40.

13. Castilla-Puentes RC, Habeych ME. Subtypes of depression among patients with Alzheimer's disease and other dementias. Alzheimer's Dement. 2010;6:63-69. http://doi.org/10.1016/j. jalz.2009.04.1232.

14. McEwen BS, Sapolsky RM. Stress and cognitive function. Curr Opin Neurobiol. 1995;5:205-216. http://doi.org/10.1016/09594388(95)90028-X.

15. Roman GC, Tatemichi TK, Erkinjuntti T, Cummings JL, Masdeu JC, Garcia JH, et al. Vascular dementia diagnostic criteria for research studies: Report of the NINDS-AIREN international workshop.
Neurology. 1993;43:250-260. http://doi.org/10.1212/WNL.43.2. 250.

16. Lezak MD, Howieson DB, Bigler ED, Tranel D. Neuropsychological assessment. 5th ed. New York: Oxford University Press; 2012.

17. Folstein MF, Folstein SE, McHugh PR. "Mini-mental state": a practical method for grading the cognitive state of patients for the clinician. J Psychiatr Res. 1975;12:189-198. http://doi.org/10.1016/0022-3956(75)90026-6.

18. Kang YO, Na DR, Hahn SH. A validity study on the Korean mini-mental state examination in dementia patients. J Korean Neurol Assoc. 1997;15:300-308.

19. Han C, Jo SA, Jo I, Kim E, Park MH, Kang Y. An adaptation of the Korean mini-mental state examination (K-MMSE) in elderly Koreans: demographic influence and population-based norms (the AGE study). Arch Gerontol Geriatr. 2008;47:302-310. http://doi.org/10.1016/j.archger.2007.08.012.

20. Shin HH, So HY, Lee AY. Comparing clinical usefulness of cognitive function tests (CDT, K-MMSE, K-3MS, CDR) in dementia patient. Korean J Rehabil Nurs. 2008;11:90-98.

21. Choi SH, Na DL, Lee BH, Hahm DS, Jeong JH, Yoon SJ, et al. Estimating the validity of the Korean version of expanded clinical dementia rating (CDR) Scale. J Korean Neurol Assoc. 2001;19:585-591.

22. Morris JC. The Clinical Dementia Rating (CDR): current version and scoring rules. Neurology. 1993;43:2412-2414. http://doi.org/10.1212/WNL.43.11.2412-a.

23. Slachevsky A, Villalpando JM, Sarazin M, Hahn-Barma V, Pillon B, Dubois B. Frontal assessment battery and differential diagnosis of frontotemporal dementia and Alzheimer disease. Arch Neurol. 2004;61:1104-1107. http://doi.org/10.1001/archneur. 61.7.1104.

24. Kim TH, Huh Y, Choe JY, Jeong JW, Park JH, Lee SB, et al. Korean version of frontal assessment battery: psychometric properties and normative data. Dement Geriatr Cogn Disord. 2010;29:363-370. http://doi.org/11.1159/000297523.

25. Kang SJ, Choi SH, Lee BH, Kwon JC, Na DL, Han SH, el al. The reliability and validity of the Korean Instrumental Activities of Daily Living (K-IADL). J Korean Neurol Assoc. 2002;20:8-14.

26. Yesavage JA, Brink TL, Rose TL, Lum O, Huang V, Adey M, et al. Development and validation of a geriatric depression screening scale: a preliminary report. J Psychiatric Res. 1983;17:37-49. http://doi.org/10.1016/0022-3956(82)90033-4.

27. Wang HX, Wahlberg M, Karp A, Winblad B, Fratiglioni L. Psychosocial stress at work is associated with increased dementia risk in late life. Alzheimer's Dement. 2012;8:114-120. http://doi.org/10.1016/j.jalz.2011.03.001.

28. Flatt JD, Gilsanz P, Quesenberry CP, Albers KB, Whitmer RA. Post-traumatic stress disorder and risk of dementia among members of a health care delivery system. Alzheimer's Dement. 2017;14:28-34. http://doi.org/10.1016/j.jalz.2017.04.014.

29. Greenberg MS, Tanev K, Marin MF, Pitman RK. Stress, PTSD, and dementia. Alzheimer's Dement. 2014;10:155-165. http://doi.org/10.1016/j.jalz.2014.04.008.

30. Bos EH, Bouhuys AL, Geerts E, van Os TW, Ormel J. Stressful life events as a link between problems in nonverbal communication and recurrence of depression. J Affect Disord. 
2007;97:161-169. http://doi.org/10.1016/j.jad.2006.06.011.

31. Fuhrer R, Dufouil C, Dartigues JF, PAQUID Study. Exploring sex differences in the relationship between depressive symptoms and dementia incidence: prospective results from the PAQUID study. J Am Geriatr Soc. 2003;51:1055-63. http://doi.org/10. 1046/j.1532-5415.2003.51352.x. 